\title{
The Power Academy in the UK: A Successful Initiative to Attract Graduates to the Power Industry
}

\author{
K.R.W. Bell, W. Fenton, H. Griffiths, J.R. McDonald and B.C. Pal
}

\begin{abstract}
The power industry in the UK faces major challenges over the next two decades to renew ageing networks and accommodate new generation, especially renewables. As a consequence, the industry needs to recruit a new generation of well-qualified electrical engineering graduates. This paper describes the IET Power Academy, established in 2004 to attract engineering graduates into employment within the power industry. In 2008, 17 companies and 7 leading UK universities are collaborating in the scheme with over 60 scholarships being offered each year. The scholarship package includes a bursary, a contribution to university fees, paid vacation training and an annual seminar. The scheme can be judged to have been a success to date, though challenges still remain, including persuading greater numbers of school and college leavers to study electrical or electronic engineering at university. As time goes on, while the industry can expect to have largely addressed issues associated with graduate recruitment, mid-career support and retention is likely to emerge as a key concern.
\end{abstract}

Index Terms-electrical engineering education; power industry; training.

\section{INTRODUCTION}

The electricity supply industry in the UK was liberalised in 1990. Between 1990 and 2004, average electricity prices paid by domestic consumers in the UK fell by nearly $30 \%$ [1] though prices have subsequently risen. The first decade of liberalisation was accompanied by a growth in the total number of individual companies involved in the UK industry - transmission owners and operators, distribution network operators, generators, retailers, manufacturers, contractors, consultancies and other service providers - and significant reductions in operating costs. For the distribution network operators, in order to meet regulatory targets, annual operating expenditure was reduced by 7.7\% between 1992 and 2003 while that of the transmission licensee in England and Wales was reduced by $4.9 \%$ [2]. A large part of these cost savings was achieved through re-orientation of staffing costs with, according to [3], workforces reduced by between $40 \%$ and $60 \%$ since the 1980s, part of it attributable to outsourcing

K.R.W. Bell and J.R. McDonald are with the Department of Electronic and Electrical Engineering, University of Strathclyde, 204 George Street, Glasgow G1 1XW, UK (e-mail: keith.bell@eee.strath.ac.uk and j.mcdonald@eee.strath.ac.uk respectively).

W. Fenton is with the The Institution of Engineering and Technology, Michael Faraday House, Six Hills Way, Stevenage, SG1 2AY, UK (e-mail bfenton@theiet.org )

H. Griffiths is with the School of Engineering, Cardiff University, The Parade, Cardiff CF23 3AA, Wales, UK. (e-mail: griffithsh@Cardiff.ac.uk )

B. C. Pal is with the Department of Electrical and Electronic Engineering, Imperial College, London, Exhibition Road, London SW7 2BT, UK (e-mail b.pal@imperial.ac.uk ) and part to downsizing.

By the early part of the $21^{\text {st }}$ century, however, the power industry in Britain was faced with two major challenges: the renewal of ageing networks; and the need to accommodate new generation, much of it renewable and located at the periphery of existing networks. While most of the network and gene-ration companies and manufacturers had continued to recruit graduates, many of them were now facing increasingly acute shortages of key skills and a difficulty in attracting the best graduates. This was against an already evident background of declining numbers of students entering electrical or electronic engineering degree courses and a decline in the proportion of undergraduates starting degrees in engineering in general.

In response to this skills shortage, the IET Power Academy was established in 2004. The Power Academy is different from previous engineering student sponsorship schemes in some key respects:

- the financial commitment made by companies is significantly higher and includes an attractive bursary and a contribution towards university tuition fees;

- it represents a coordinated effort by the main power companies, the creation of highly visible 'brand', a partnership with key universities with strong power engineering research and teaching facilities, and interaction between sponsored students from the different companies and universities, e.g. through a summer seminar, and the involvement of the Institution of Electrical Engineers (now called the IET - The Institution of Engineering and Technology - after a merger with the Institution of Incorporated Engineers in March 2006);

- the acknowledgement that the collective interests of the consortium of companies are greater than the companies' individual needs and that, through this co-operation, there would be continual improvement in the provision of training and support to students.

This paper describes the IET Power Academy scheme, its main aims and its form. It addresses how it has fared so far and discusses future prospects.

\section{SKILLS SHORTAGES IN THE UK POWER SECTOR}

\section{A. New industry challenges}

In spite of the reduction in operating costs in the electricity supply industry in the UK since 1990, capital investment in the has nonetheless continued: to accommodate a modest growth in demand for electricity and a rolling programme of 
asset replacement, and particularly to support the development of new generation, the extent of which is shown in Figure 1 against a background of peak demand in England and Wales in 2001 of around 50GW.

The total capital expenditure by the various distribution network operators (DNOs) and transmission licensees (TSOs) over the period 1990 to 2004 was $£ 15$ billion and £6 billion respectively [2]. However, for reasons that will be discussed below, these levels of investment need to be dramatically increased.

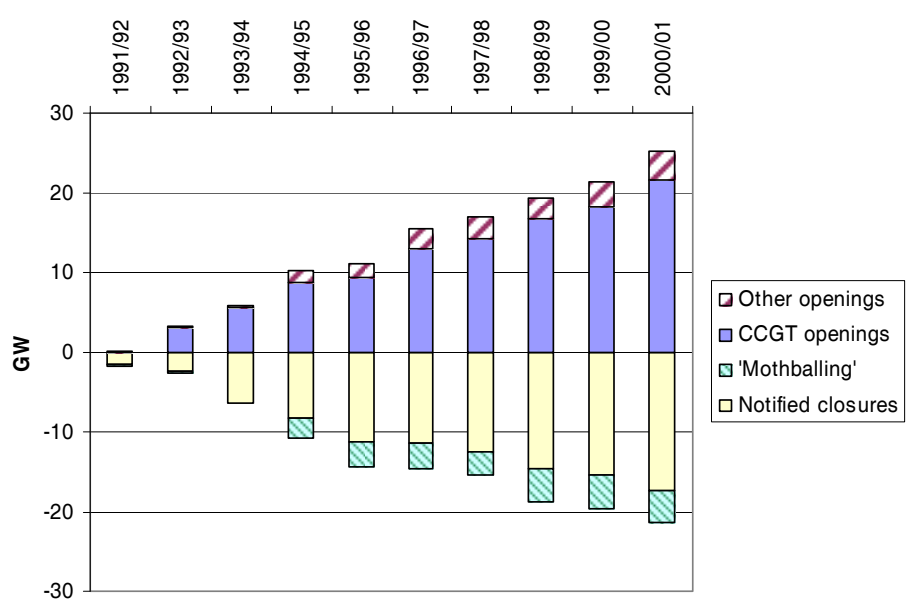

Figure 1: cumulative change in generation capacity in England and Wales, 1991$2000[4]$

\section{1) Renewal of an ageing electricity infrastructure}

Peak expenditure on distribution networks occurred in 1965 and reduced to a minimum in the early 1980s [5]. Working on the assumption of a 40-50 year nominal plant life, large parts of the UK electricity network infrastructure are now reaching their nominal end-of-life. As the condition of many of these old assets declines and repair becomes uneconomic, a massively increased investment in replacement is required. In addition, a number of commentators in the UK, e.g. [6], have pointed towards the closure of ageing coal and nuclear generation and warned that up to a third of Britain's total generating capacity may close by 2015 and need to be replaced.

\section{2) Meeting the climate change challenge}

The UK Government's report on its Energy Review [7] addresses the Carbon Challenge. The report points to the need to both save energy and use cleaner sources of energy. One of the central policies emerging from the review is the commitment to produce $20 \%$ of electricity from renewables by 2020, much of this coming from large off-shore wind schemes. With the longer-term challenge of reducing $\mathrm{CO}_{2}$ emissions by $60 \%$ by 2050 , some believe that the contribution made by renewable electricity generation will need to be significantly higher than $20 \%$ by 2020 . The European Commission's 2006 Green Paper 'A European Strategy for Sustainable, Competitive and Secure Energy' emphasised that "Europe has now entered a new energy era" and that objectives must include sustainability and security of energy supply [8].

Boosted by Government-led incentives, generation developers are responding to the challenge. From a total wind generation capacity of less than $3 \mathrm{GW}$ in 2008 [9], the transmission licensees in Britain had, by May 2008, made offers of connection to accommodate a further $12 \mathrm{GW}$ of wind generation by the end of 2014 [10]. By far the greatest part of this capacity is due to connect in the north of Britain or offshore, far from the main demand centres in the south of Britain. The utilisation of this generation therefore requires considerable investment in additional transmission capacity, estimated to cost upwards of $£ 560$ million for the first phase of expansion in Scotland and northern England alone [11]. In addition, growth of distributed generation connected at voltages of $132 \mathrm{kV}$ or below has long been anticipated and presents major challenges. The distribution system will have to change radically to accommodate bi-directional power flows and utilise 'active network management'. Higher levels of automation and active control of power flow are likely to require more intensive application of power electronics and investment in advanced communication systems.

\section{3) The need for skills}

The net effect of the aforementioned developments is that, over the current distribution price control period (2005-2010), the DNOs in the UK are expected to have invested around $£ 5.7$ billion [12] with a significant increase expected over the next price control period. Between 2008 and 2012, National Grid, which owns and operates the transmission system in England and Wales - is expected to invest $£ 7.5$ billion [2].

This significant ramping-up of investment in the electricity supply industry in the UK and the major engineering challenges associated with it will require a well-developed foundation of people and skills. This requirement is faced by not only by the DNOs and transmission licensees, but also equipment manufacturers, generating companies, contractors and consultants. Among the skills that an expanded workforce should possess are:

- engineering design and analysis;

- $\quad$ project management;

- commissioning;

- power system planning;

- asset management;

- power system operation.

Not all the tasks associated with the above activities require graduate engineers. UK bodies such Energy and Utility Skills and the new National Skills Academy for Power, announced in November 2008, have, among their objectives, the promotion of apprenticeships and the take-up of vocational training in further education. However, as will be described more fully in the next section, in recent years there has been a significant decline in the number of undergraduates studying electrical or electronic engineering in the UK. In addition, the UK population of 18 year olds is set to fall by nearly 15\% between 2009 and 2018 [13]. If the power 
industry is to find enough high quality graduates to deliver the required programme of investment, action is required. It is this that has motivated the formation of the Power Academy.

\section{B. Engineering in the UK higher education sector}

Figure 2 shows the numbers of students accepted to begin studies in electrical and electronic engineering (EEE) at UK higher education institutions between 2002 and 2007. Also shown for comparison are the total numbers of students accepted to study aero or mechanical engineering, civil engineering and engineering as a whole. While the numbers for engineering as a whole can be seen to have remained fairly constant through that period, those for EEE show a 35\% fall. Against a background of significantly rising numbers of undergraduates overall, however $(344,000$ accepted to begin study in 2002 rising to 405,000 in 2007), the proportion of students studying both EEE and any form of engineering show substantial falls (Figure 3) [14]. Furthermore, a significant number of electrical and electronic engineering students are enrolled on courses that are not accredited by the main professional body in the UK, the IET.

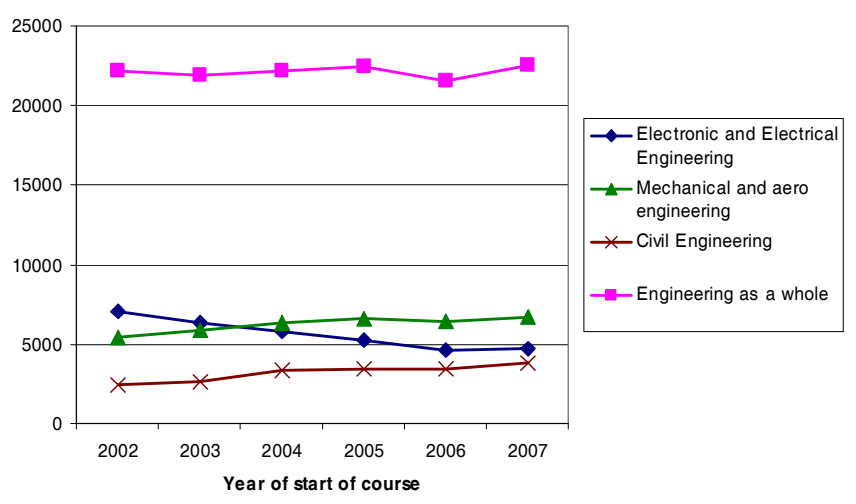

Figure 2: acceptances for study at UK higher education institutions [14]

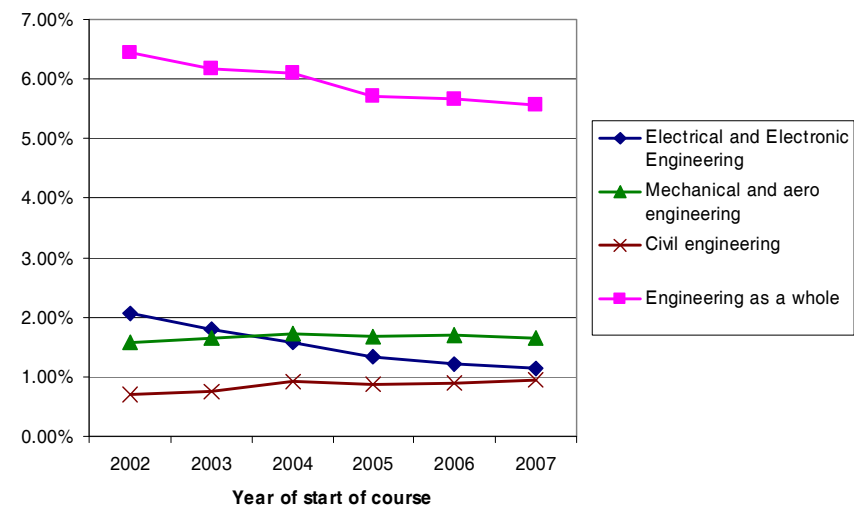

Figure 3: acceptances for study at UK higher education institutions as proportions of the total acceptances for all subjects [14]

A number of commentators have offered explanations for the apparent decline of interest in science, technology, engineering and mathematics in the UK. For example, in [15], it was suggested that school age students feel the science curriculum is too theoretical or not relevant, that there is a shortage of specialist science teachers and that both students and teachers show a poor understanding of the career options available in science or technology.

\section{POWER ACADEMY AIMS AND PARTNERS}

The stated mission of the Power Academy upon its foundation in 2004 was

To address with quality power companies and universities the shortfall in engineering expertise in the electricity power industry by attracting new talent into the industry, primarily at undergraduate level leading to graduate employment.

Company partners would be committed to providing financial support for scholars, well-planned and challenging summer training and an active role in the Power Academy recruitment process. University partners would be responsible for promoting the scheme among their students, enabling students to apply to join it and preparing them for their summer placements. The university representatives also monitor Power Academy scholars' academic performance and make themselves available to support scholars in the event of any issues arising.

The various university and company partners of the Power Academy are listed in Tables 1 and 2 along with their years of joining and the numbers of Power Academy scholars they have supported up to and including the academic year 2008/9. Most companies' support has remained constant or increased though that period. As more universities have joined the scheme, the companies are selecting from a wider pool. In a university's first year in the scheme, new scholars tend to come from all years of an undergraduate population. Afterwards, with older students already being on the scheme, new scholars tend to be found from among first years.

TABLE 1: POWER ACADEMY UNIVERSITY PARTNERS

\begin{tabular}{|l|c|r|r|r|r|r|r|}
\hline & Year joined & \multicolumn{6}{|c|}{ Number of scholars } \\
\cline { 3 - 10 } & scheme & $\mathbf{2 0 0 4}$ & $\mathbf{2 0 0 5}$ & $\mathbf{2 0 0 6}$ & $\mathbf{2 0 0 7}$ & $\mathbf{2 0 0 8}$ & Total \\
\hline University & 2006 & n/a & n/a & 7 & 7 & 5 & $\mathbf{1 9}$ \\
\hline Imperdiff University College London & 2006 & n/a & n/a & 11 & 3 & 9 & $\mathbf{2 3}$ \\
\hline Queen's University, Belfast & 2004 & 2 & 11 & 4 & 2 & 1 & $\mathbf{2 0}$ \\
\hline University of Bath & 2008 & n/a & n/a & n/a & n/a & 5 & $\mathbf{5}$ \\
\hline University of Manchester & 2004 & 17 & 9 & 8 & 7 & 5 & $\mathbf{4 6}$ \\
\hline University of Southampton & 2004 & 5 & 6 & 3 & 8 & 8 & $\mathbf{3 0}$ \\
\hline University of Strathclyde & 2004 & 17 & 15 & 14 & 16 & 24 & $\mathbf{8 6}$ \\
\hline
\end{tabular}

Management of the Power Academy is achieved through an Executive and a Council. The 10-member Executive comprises a chairman nominated by the company partners, 4 further company partner representatives, 3 university representatives (one of whom is the vice chairman), a representative from Energy \& Utility Skills and one from the IET. The larger Council comprises one representative from each partner organisation, Energy and Utility Skills and the IET. 
TABLE 2: POWER ACADEMY COMPANY PARTNERS

\begin{tabular}{|c|c|c|c|c|c|c|c|c|}
\hline \multirow[b]{2}{*}{ Company } & \multirow{2}{*}{$\begin{array}{c}\text { Year } \\
\text { entered } \\
\text { scheme }\end{array}$} & \multirow[b]{2}{*}{ Main Power Academy business activity } & \multicolumn{6}{|c|}{ No. of scholars supported } \\
\hline & & & 2004 & 2005 & 2006 & 2007 & 2008 & Total \\
\hline ABB & 2005 & Power equipment manufacturer & $\mathrm{n} / \mathrm{a}$ & 1 & 2 & 2 & 3 & 9 \\
\hline AREVA T\&D & 2005 & Power equipment manufacturer & $\mathrm{n} / \mathrm{a}$ & 0 & 2 & 2 & 2 & 6 \\
\hline Atkins & 2005 & Consultancy & $\mathrm{n} / \mathrm{a}$ & 0 & 2 & 2 & 2 & 6 \\
\hline CE Electric & 2004 & Distribution network operator & 2 & 1 & 3 & 1 & 1 & 8 \\
\hline E.On & 2004 & Distribution network operator & 8 & 9 & 5 & 8 & 11 & 41 \\
\hline EA Technology & 2004 & Power networks research institute & 1 & 2 & 1 & 1 & 0 & 5 \\
\hline EDF Energy & 2004 & Distribution network operator & 6 & 7 & 9 & 8 & 7 & 37 \\
\hline Jersey Electricity & 2005 & Distribution network operator & $\mathrm{n} / \mathrm{a}$ & 0 & 0 & 0 & 0 & 0 \\
\hline National Grid & 2004 & Transmission system owner and operator & 15 & 3 & 7 & 5 & 14 & 44 \\
\hline NIE & 2004 & Transmission and distribution system owner and operator & $\mathrm{n} / \mathrm{a}$ & 2 & 3 & 2 & 0 & 7 \\
\hline Rolls Royce & 2007 & Power equipment manufacturer & $\mathrm{n} / \mathrm{a}$ & $\mathrm{n} / \mathrm{a}$ & $\mathrm{n} / \mathrm{a}$ & 3 & 3 & 6 \\
\hline RWEnpower & 2008 & Generator & $\mathrm{n} / \mathrm{a}$ & $\mathrm{n} / \mathrm{a}$ & $\mathrm{n} / \mathrm{a}$ & $\mathrm{n} / \mathrm{a}$ & 5 & 5 \\
\hline Scottish \& Southern & 2004 & Transmission and distribution system owner & 1 & 1 & 1 & 1 & 1 & 5 \\
\hline Scottish Power & 2004 & Transmission and distribution system owner & 3 & 3 & 4 & 2 & 2 & 14 \\
\hline Siemens & 2005 & Power equipment manufacturer & 2 & 8 & 5 & 2 & 2 & 19 \\
\hline UKAEA & 2007 & Nuclear power research institute & $\mathrm{n} / \mathrm{a}$ & $\mathrm{n} / \mathrm{a}$ & $\mathrm{n} / \mathrm{a}$ & 1 & 2 & 3 \\
\hline United Utilities & 2004 & Distribution network operator & 2 & 2 & 2 & 1 & 0 & 7 \\
\hline Western Power & 2004 & Distribution network operator & 1 & 2 & 1 & 2 & 2 & 8 \\
\hline
\end{tabular}

The Executive's role is to prompt and monitor continuing performance improvement of all partners, provide strategic direction, lobby Government and act as a champion for the Academy. The Council's role is to develop detailed policy, monitor the implementation of policy, address any issues that arise, and drive the continuing performance improvement of the Academy as a whole.

The IET's role is to provide professional advice and support and management services along with marketing and publicity and a high level brand for the Academy. One important publicity tool provided by The IET is the Power Academy website: http://www.theiet.org/about/scholarshipsawards/power-academy/

\section{SCHOLARS' BENEFITS AND ADMISSION OF NEW SCHOLARS}

In 2008, students supported by the Power Academy, i.e. Power Academy 'scholars', receive the following benefits:

- a bursary of $£ 2,200$ per annum;

- a book allowance of $£ 220$ per annum;

- a financial contribution towards university fees;

- at the end of each year on the scheme before the graduation year,

- a Summer Seminar;

- a minimum of eight weeks paid vacation training experience;

- a Company Mentor;

- free IET Student Membership for the duration of the degree course.

Continuation on the scheme is dependent on satisfactory performance academically and on the summer placements.

The main point of sponsorship is to build up a relationship between company and scholar. The bursary, while much appreciated by scholars, does not guarantee conversion to employment. It might be argued that spending a few thousand pounds a year on an undergraduate is an unnecessary cost. However, companies have long been accustomed to paying to train their apprentices, and apprentices all earn a reasonable salary and tend not to end their training in debt. Indeed, they will very likely have managed to enter the housing market long before a graduate. If school and college leavers are to be encouraged to study for engineering degrees that very often leave students in debt, it would seem reasonable for the companies that benefit from their knowledge and skills to make some contribution to the cost of their studies.

The main way in which potential new Power Academy scholars learn about the scheme is via universities, either at the stage of applying for entry to a course or soon after they have started. (In 2008, 83\% of the 240 applicants heard of the Power Academy that way).

To be eligible to join the scheme, an applicant must be a current student in the electronic and electrical engineering department of one of the partner universities listed in Table 1.

The timeline for applications is as shown in Table 3. Application forms from students are submitted on-line to the IET and applicants are able to express a preference for up to three partner companies or ask to be considered by all of them. From this initial list of students, a first shortlist is drawn up on behalf of all the company partners by a panel comprising company members of the Council. Shortlisted applicants are then invited to 'assessment centres' hosted at each of the partner universities. The assessment centres are run by nominated company representatives on behalf of all company partners. In 2008, this first assessment took the form of a short presentation by each individual candidate, a group exercise and individual interviews.

Based on feedback from the assessment centres, individual companies conduct detailed reviews of the applications pertaining to their company. Following this review, selected applicants are invited to a further assessment day at the company. Individual candidates may be invited to these second-stage assessments with up to three companies and may subsequently be able to choose between a number of offers. 
TABLE 3: POWER ACADEMY RECRUITMENT TIMELINE

\begin{tabular}{|l|l|}
\hline Date & Activity \\
\hline End of October & Closing date for applications \\
\hline November, week 3 & $1^{\text {st }}$ stage assessment centres at universities \\
\hline December, week 1 & $\begin{array}{l}\text { Invitations to }\left(2^{\text {nd }} \text { stage }\right) \text { company } \\
\text { assessments }\end{array}$ \\
\hline December, week 3 & Company assessments \\
\hline End of December & Offers or regrets sent out \\
\hline January, week 2 & Deadline for acceptance of offers \\
\hline March & Conclusion of 'clearing' process \\
\hline July-September & Summer placements \\
\hline
\end{tabular}

Following the acceptance of offers by successful students, some scholarship places may remain unfilled and some candidates have not received offers. The remaining students are considered by companies in a third 'clearing' stage.

Once an applicant has accepted an offer with a company, while they become a Power Academy scholar and are entitled to the common benefits, the main relationship is between the individual scholar and the company. The scholar's university provides backup in the event of any issues arising as well as a good engineering education.

\section{EXPERIENCE OF THE SCHEME}

\section{A. Scholars' experiences}

Tables 1 and 2 above show the numbers of scholars that have been admitted to the Power Academy. As expected, in the first year of participation by a university, recruitment to the scheme occurs across all years of the degrees. However, in subsequent years, the majority of applications are received from first-year students.

Scholars are supported on 3-year BEng (Hons) or 4-year MEng courses in England, Wales and Northern Ireland or 4year BEng (Hons) or 5-year MEng courses in Scotland. With the scheme only being established in 2004 and the majority of scholars not yet having come through to graduation, there is not yet a substantial volume of evidence for whether the scheme has met one of its aims, that of encouraging electrical engineering undergraduates to take jobs with the partner companies. However, some indications of whether they are likely to can be gleaned from the annual survey of scholars conducted at the summer seminar.

Successive surveys have shown that the great majority of scholars have a positive experience of the Power Academy, their companies and power engineering. However, as well as the scholars developing their engineering and business knowledge, the surveys have also shown that, in some respects, the companies have been learning as the scheme has gone on and improving their training provision. The trend of continual improvement is boosted by the nature of the scheme as a collaboration between many companies, in two main respects:

1. companies are prepared to share what they have learned with other, so enabling a general improvement to the overall benefit of all concerned;

2. while the terms and conditions offered to scholars are broadly the same, scholars will discuss their different experiences with scholars from other companies; moreover, while companies are not obliged to make offers of full-time employment to scholars, neither are scholars obliged to accept them and they may apply to companies other than those that supported their scholarship. The result is that companies are still, in effect, in competition with each other.

\section{B. Company partners' engagement with scholars}

Perhaps the two most important influences on scholars' experiences of the scheme are:

1. the quality of the summer training placements;

2. the nature of the contact between the scholar and the company during term-time.

The second of the above is something that is increasingly recognised by the company partners. For example, companies can make a good impression on their scholars and help them feel included in the company culture by means of quite simple measures like sending them new editions of staff magazines or meeting them at the university every so often and taking them out to lunch. One of the most important things for the scholar is that they receive their bursary on time. They also value early notice of plans for the forthcoming summer placement and due recognition of their preferences for that placement.

The sorts of placement activities that have been offered by the companies include:

- quantification of transmission system losses and evaluation of different commercial arrangements for recovery of the cost of those losses;

- a case study on the benefits of voltage control equipment at wind farms connected on lightly loaded radial networks;

- type registration of under-frequency load shedding equipment with laboratory testing of equipment functionality and production of thorough documentation;

- the development of artificial intelligence to detect and report hidden faults on substation ethernet networks.

The effective planning and implementation of the summer placements is critical to the success of the overall scheme and can be seen through the annual survey of scholars to have been steadily improved. Not only should company partners provide good training so that when scholars finally reach employment, ideally with the company through which they were sponsored, they will become effective engineers more quickly, but also they should also give as good an impression as possible of the attractiveness of a career in power engineering. All company partners on the scheme should continue to be committed to monitoring and reviewing placements to ensure that the above objectives are achieved.

The summer experience is enhanced by the provision of a 2-day seminar attended by all scholars. As well as enabling scholars to meet each other, share experiences, socialise and offer feedback to the Power Academy partners, it affords an excellent opportunity to meet leading industry figures and 
debate power and energy topics with them. On the companies' part, the participation in the seminar of senior figures such as chief executives is a sign of their commitment to the scheme.

\section{Universities' experiences}

All the Power Academy partner universities already have strong industrial links through research and support of $\mathrm{PhDs}$ as well as at undergraduate level. The Power Academy connection further strengthens that link and contributes to the industrial relevance of degree programmes. In addition, the partner universities benefit from being able to make reference in their undergraduate prospectuses to the availability of Power Academy scholarships. Of course, the attractiveness of a scholarship is part of the point of the Power Academy, intended as it is to persuade a school or college leaver to study electrical engineering rather than something else. However, evidence for whether it is succeeding in doing that is currently scant. For example, $83 \%$ of applicants to the Power Academy in 2008 had heard about it through university; this is likely to have been after they had already decided to study electrical and electronic engineering. What does seem likely, though, is that the scheme is persuading EEE undergraduates to specialise in power rather than, for example, communications.

\section{FUTURE CHALLENGES}

The continued commitment of the Power Academy partners to the scheme and the positive responses given by scholars is an indication of the success of the scheme. However, a number of challenges remain and are discussed below.

\section{A. Attracting school and college leavers to engineering}

One of the objectives of the Power Academy company partners is to persuade more school and college leavers to study electric power engineering and to encourage Power Academy scholars to progress to careers in the power industry. This fits well with the UK Government's view that a "strong supply of scientists, engineers and technologists" will be essential to give UK businesses and public services "the drive and capability to innovate" [16].

One of the best ways to reach school and college leavers and influence their choices of degree is through the school or college. However, there are more than 2500 secondary schools in the UK making it time-consuming and expensive to reach each one. These schools are currently targeted by mailshots from the IET, but the effectiveness of this is always open to question. There is also a need to provide information to the right people within a school or college. The obvious target might be the careers advisor but, in practice, it may be better to address information to physics or maths teachers who might have a better appreciation of what the material is about.

\section{B. Career development for engineers}

Early indications suggest that the company partners can be confident that the Power Academy will make a significant contribution to their graduate recruitment. However, challenges remain in the retention of staff. Anecdotally, this seems to be particularly true for engineers who have completed their training and served a few years in their first responsible position. Given the volume of investment being undertaken by the industry in the UK and the role of contractors in delivering projects, there is a vibrant market for experienced commissioning engineers and project managers and a significant 'churn' of staff between different companies. However, for plant specialists, power system planners and power system operators, for example, the opportunities to progress through mid-career seem to be limited and are leading experienced engineers to move into commercial or purely management roles. This leaves the risk that industry's engineering leadership might not be sufficiently welldeveloped to be able to respond to the major technical challenges associated with, among other things, the integration and operation of wind farms or active management of distribution networks.

\section{Recruitment and training of researchers}

One of the perhaps unanticipated effects of the Power Academy and a function of its success has been that it has become more difficult to persuade some of the best undergraduates to stay on at university to do postgraduate research. One response to this, motivated as much by concern for development of the next generation of academics as for delivering research in the short-term, has been the establishment of the 'Power Networks Research Academy' (PNRA) in 2007. This scheme supports a small number of $\mathrm{PhD}$ projects across the Power Academy universities, with financial contributions made by a subset of the network companies from the Power Academy and the UK 'Engineering and Physical Sciences Research Council' $($ EPSRC). Although it is still in its early stages of operation, the main feature of this scheme to date has been the significant boost given to stipends rather than any particular innovation in respect of training or career development. However, the importance of PhD study, through whichever of the many possible avenues, and the additional skills that a research student can develop over and above what is learned on a conventional graduate route, should not be underestimated. $\mathrm{PhD}$ graduates from the best institutions will not only have deeper knowledge than Bachelor's or Master's graduates and at least equal inter-personal skills and industry awareness (which industrial collaboration can develop further) but also enhanced problem solving capabilities and imagination. These skills will be essential to the future industrial engineering leadership described earlier and should not be neglected by employers.

\section{International recruitment}

The effect of the Power Academy on postgraduate research recruitment as a whole accentuates a phenomenon that has been observed in electrical and electronic engineering departments at UK universities for some years. This is an 
increasing dependency on international students and contract researchers for the delivery of research projects and realisation of research leaders' vision and creativity. It has been possible to give opportunities to excellent engineers from all around the world who are now an extremely important part of the UK workforce, but it does require both students and host institutions to be sensitive to any cultural or language issues that might arise and become obstacles to effective research. It may also be questioned whether this sets in motion a 'brain drain' of talent away from less developed economies [17].

Some power companies in the UK have also responded to the recruitment challenge by importing experienced engineers from outside Europe. However, the Power Academy has not been opened up to non-European Union students, the argument being that these students do not currently require that degree of persuasion to enter the UK power industry. While that may be so, it presents some difficulties to academics at a number of the partner universities where 50\% or more of the engineering undergraduate population are international students who already pay significantly higher fees than their 'home' counterparts and yet see themselves as being denied the same opportunities that their classmates enjoy.

\section{E. Following the Power Academy's lead}

The success of the Power Academy will cause it to have to work harder as other engineering sectors follow its example and establish rival academies. While not in direct competition, the Power Academy in the UK has already inspired the Japan Power Academy (which is mainly concerned with research) and the IET Power Academy Australia.

In view of the contributions that engineers make to economic life and society as a whole, if rival academies in the UK succeed in attracting more young people to careers in engineering, it should be seen as a good thing.

\section{$F$. The future engineering graduate}

A recent study commissioned by The Royal Academy for Engineering [18] suggested that the engineering graduate of the future will fill three key roles:

1. that of engineer as specialist, recognising the need for world-class technical experts;

2. that of engineer as 'integrator', reflecting the need for graduates "who can operate and manage across boundaries, be they technical or organisational, in a complex business environment";

3. that of engineer as 'change agent', highlighting "the critical role engineering graduates must play in providing the creativity, innovation and leadership needed to guide the industry to a successful future".

The Royal Academy's report concluded by emphasising the responsibility of the engineering industry in ensuring the future excellence of undergraduate engineering education in the UK. Through the Power Academy, a number of major companies in the UK power sector have taken significant steps, in partnership with leading university electrical and electronic engineering departments, to doing just that. Moreover, the collaboration between all the Power Academy partners affords a stronger collective voice through which to contribute to the wider national debate on investment in skills and training and to influence Government policy.

\section{CONCLUSIONS}

This paper has described two major challenges faced by the power industry in the UK, in respect of renewal of an ageing power infrastructure and the accommodation of renewable and distributed generation, and the background conditions that are making it difficult to attract adequate numbers of high quality graduates. One of the industry's responses has been for a group of companies to collaborate with each other and with a core group of leading UK electric power engineering universities in the Power Academy, supported by the IET.

The Power Academy aims to attract school and college leavers into electrical engineering degrees, and electrical engineering graduates into the power industry. It offers financial support to students who have succeeded in being admitted to the scheme. Most importantly, it enables a relationship to be built between sponsoring power companies and scholars. This relationship is critical to the scheme's success, which, for the companies, means conversion of the best scholars to employment and, for scholars, means finding an attractive and rewarding career route. The key factor in building the relationship is the nature and challenge of summer placements with the sponsoring company. Almost as important is communication between company and scholar throughout the year and the support given by a company mentor. The Power Academy's summer seminar is also an invaluable opportunity for the industry to demonstrate what it has to offer in the exciting and challenging times ahead.

To raise the delivery standard of the Power Academy, all partners have agreed performance process models and the sharing of best practice.

It has been argued that, since its foundation in 2004, the Power Academy has been a success with increasing numbers of scholars coming onto the scheme and a significant majority of positive responses being found in annual surveys of their experiences. However, the level of influence it has on the degree choices by school and college leavers is yet to be determined and remains a challenging area, not only for the Power Academy partners but also for the UK government in respect of its overall skills agenda. One of the benefits of the Power Academy partnership is that collective effort gives the best chance of addressing this challenge and of influencing the government in its future course of action.

As time goes on, while the industry can expect to have largely addressed graduate recruitment issues, mid-career support and retention is likely to emerge as a key concern. 


\section{REFERENCES}

[1] Department for Business, Enterprise and Regulatory Reform, Quarterly Energy Prices, available: http://www.berr.gov.uk/whatwedo/energy/statistics/publi cations/prices/index.html

[2] Alistair Buchanan, Chief Executive, Office of Gas and Electricity Markets, Speech at SBGI, March 6, 2008.

[3] Somia Nasim, Sector Skills Agreement Stages 1 and 2: Report on the electricity industry, Energy and Utility Skills, December 2006, available: http://www.euskills.co.uk/home/resources.php?folder=7 0

[4] National Grid Company plc, 2002 Seven Year Statement, Coventry, May 2002.

[5] Mike Kay, "The Investment Challenge - Things to Come", IET Power Convention, September 10-11, 2007.

[6] Paul Golby, Chief Executive, E.ON UK "E.ON UK: Our Business Model", E.ON Capital Market Day UK, June 29, 2005, available: http://www.eon.com/en/downloads/ConferenceCall_cmd _050629_charts_golby.pdf

[7] Department of Trade and Industry, The Energy Challenge: Energy Review Report, 2006.

[8] Commission of the European Community, A European Strategy for Sustainable, Competitive and Secure Energy, SEC (2006) 317, Brussels, 2006

[9] British Wind Energy Association, UK Wind Energy Database: http://www.bwea.com/ukwed/index.asp

[10] National Grid Electricity Transmission, 2008 Seven Year Statement, Warwick, May 2008, available: http://www.nationalgrid.com/uk/Electricity/SYS/

[11] Office of Gas and Electricity Markets, Transmission investment for renewable generation: Final proposals, Ref. 288/04, December 2004, available: http://www.ofgem.gov.uk/Networks/Trans/PriceControls /TPCR4/ConsultationDecisionsResponses/Documents1/ 9139-28804.pdf

[12] Office of Gas and Electricity Markets, Electricity Distribution Price Control Review Final Proposals, Ref. 265/04, November 2004, available: http://www.ofgem.gov.uk/Networks/ElecDist/PriceCntrls /DPCR4/Documents1/8944-26504.pdf

[13] The Engineering and Technology Board, Engineering UK, 2007, December 2007, available: http://www.etechb.co.uk/_db/_documents/EngUK07.pdf

[14] UCAS statistics online, available: http://www.ucas.com/about_us/stat_services/stats_online /

[15] Cliff Porter and Joy Parvin, "Learning to Love Science", The Chemical Industry Education Centre, 2008.

[16] HM Treasury, PSA Delivery Agreement 4: Promote world class science and innovation in the UK, 2007.

[17] Katerina Rudiger, Towards a Global Labour Market? Globalisation and the Knowledge Economy, The Work Foundation, London, June 2008

[18] Henley Management College, Educating Engineers for the 21 $1^{\text {st }}$ Century: The Industry View, The Royal Academy for Engineering, March 8, 2006, available: http://www.raeng.org.uk/news/releases/henley/pdf/henle y_report.pdf

\section{ACKNOWLEDGEMENTS}

The contribution made by Karen Li of the IET in collating Power Academy statistics is gratefully acknowledged.

\section{BIOGRAPHIES}

Keith Bell is a Senior Lecturer in the Department of Electronic and Electrical Engineering at the University of Strathclyde in Glasgow. He graduated with a BEng (Hons) and $\mathrm{PhD}$ in electrical engineering from the University of Bath in 1990 and 1995 respectively. Between 1998 and when he joined Strathclyde in 2005, Keith worked with National Grid in Warwick, England. Keith is a member of CIGRE Study Committee C1 on System Development and Economics and of the IET Power Academy Council. His research interests include power system planning and operation, electricity markets, regulation and grid integration of renewables. He is a Member of the IET and a Chartered Engineer. Bill Fenton is the Manager of the IET Power Academy. After a career in the pre and post privatised electricity industry, he became Chief Executive of the Electricity Training Association, the National Training Organisation for the UK power sector, from 1993 to 2003. In 2004 he joined the IET on a part-time basis to help set up and manage the day to day operations of the Power Academy and more recently the Power Networks Reseach Academy. Bill is also the UK Director of Training for the French international standards certification body AFNOR Groupe.

Huw Griffiths is a Senior Lecturer in the School of Engineering at Cardiff University and a member of the Power Academy Council. He joined the South Wales Electricity Board in 1978 as an apprentice and graduated with a degree from the Polytechnic of Wales in 1982. From 1984-1990, he was with the Central Electricity Generating Board (CEGB) working in transmission system design and planning. He was appointed to the lecturing staff at Cardiff in 1990 and his research interests include power system earthing and transients.

Jim McDonald received his BSc, MSc, and PhD degrees from the University of Strathclyde in Glasgow. He was appointed as the Rolls-Royce Chair in Electrical Power Engineering in 1994 and was made Head of Department in 2003. He has been Director of the Institute for Energy and Environment at the University of Strathclyde and, in early 2009, was appointed Principal and Vice Chancellor of the University of Strathclyde. His research activities are in the areas of power system protection and management, expert systems applications in power engineering, and energy management. He is a member of the Power Academy Executive, the author of many technical papers, a co-author of two books and a Senior Member of the IEEE

Bikash Pal (M'00-SM'02) received the B.E.E. (with honours) degree from Jadavpur University, Calcutta, India, the M.E. degree from the Indian Institute of Science, Bangalore, India, and the Ph.D. degree from Imperial College London, U.K., in 1990, 1992, and 1999, respectively, all in electrical engineering. Currently, he is a Reader in the Department of Electrical and Electronic Engineering, Imperial College London and is a member of the Power Academy Council. His current research interests include state estimation, power system dynamics and flexible AC transmission system controllers. 